Revista Destaques Acadêmicos, Lajeado, v. 9, n. 1, 2017. ISSN 2176-3070 DOI: http://dx.doi.org/10.22410/issn.2176-3070.v9i1a2017.1316 www.univates.br/revistas

\title{
ADOÇÃO DAS NORMAS INTERNACIONAIS DE CONTABILIDADE PELAS PEQUENAS E MÉDIAS EMPRESAS DO VALE DO TAQUARI
}

\author{
Edemar Silveira de Avila ${ }^{1}$, Adriano José Azeredo²
}

Resumo: O processo de convergência das IFRS for SMEs foi regulamentado no Brasil pela Resolução CFC n ${ }^{\circ}$ 1.255/2009 que aprovou a NBC TG 1000. A adoção da referida norma brasileira de contabilidade aplicada a pequenas e médias empresas, trouxe para elas benefícios e desafios. Direciona-se este estudo a identificá-los, bem como analisar o índice de adequação destas empresas. Para a realização do estudo, de caráter qualitativo e quantitativo, coletaram-se demonstrações contábeis referente ao exercício findo de 2015 de 150 pequenas e médias empresas da Região do Vale do Taquari - RS que possuem contabilidade em escritórios terceirizados. Na primeira etapa do tratamento dos dados, foi aplicado um checklist adaptado do CRC/RS na totalidade da amostra. Na segunda etapa, para fins de validação dos resultados do checklist foram selecionadas 10 empresas, dentre as 150, para aplicação de entrevistas junto a seus gestores. A pesquisa revelou que as demonstrações contábeis das empresas não estão condizendo com os fatos que elas praticam. Foi constatado que $75 \%$ das respostas apresentaram divergência nos dados fornecidos pelas empresas aos escritórios de contabilidade. Conclui-se que se as empresas não estão transparecendo todas as informações necessárias para a elaboração das demonstrações contábeis, certamente o escritório de contabilidade não terá condições de fazê-lo de forma precisa.

Palavra-chave: IFRS para PMEs. NBC TG 1000. Identificar os principais benefícios.

\section{INTRODUÇÃO}

No Brasil, o panorama da econômica tende a influenciar a estabilidade dos negócios, principalmente, das Microempresas e Empresas de Pequeno Porte (MPE), que ao longo dos anos assumiram um papel econômico importante no desenvolvimento do nosso país. A relevância do desempenho apresentado por

1 Graduado em Ciências Contábeis pelo Centro Universitário UNIVATES.

2 Mestre em Ciências Contábeis pela Universidade do Vale do Rio dos Sinos (2008). Professor do da Univates. 
elas está na ampla representatividade na produção de bens e serviços, bem como, na geração de emprego e renda.

De acordo com pesquisa do Serviço de Apoio às Micro e Pequenas Empresas (SEBRAE), em 2011 as MPE respondiam por 52\% dos empregos com carteira assinada no Brasil e pela geração de $27 \%$ do Produto Interno Bruto (PIB) (SEBRAE, 2014).

Assim, as MPE brasileiras foram inseridas no processo de adoção das Normas Internacionais de Contabilidade (IFRS - International Financial Reporting Standards). As demonstrações financeiras preparadas de acordo com as IFRS têm como objetivo: revelar de forma transparente informações em relação à posição financeira, o desempenho e os fluxos de caixa das empresas. Essas demonstrações são destinadas a usuários externos, sendo esses proprietários que não estão envolvidos na administração do negócio, credores existentes e potenciais e agências de avaliação de crédito. (GIROTTO, 2010).

Com este cenário estabelecido, buscou-se em 150 (cento e cinquenta) empresas pertencentes à carteira de clientes de um escritório de contabilidade localizado no Vale do Taquari, estado do Rio Grande do Sul, identificar os principais benefícios que as empresas possuem em adotar as Normas Internacionais de Contabilidade. As informações se referem ao exercício de 2015 e a respectiva legislação vigente.

Este trabalho se justifica pelo preenchimento de lacunas de conhecimento que existem nos profissionais de Contabilidade que atuam nas empresas de serviços contábeis. A adoção das IFRS permite que as empresas tenham a Contabilidade como uma ferramenta para a tomada de decisão, maior credibilidade no mercado em razão da transparência das informações e demonstrações financeiras mais acessíveis para os investidores.

\section{REFERENCIAL TEÓRICO}

A importância das pequenas e médias empresas para a economia, não se restringe ao Brasil, fazendo com que International Accounting Standards Board (IASB) elaborasse uma norma de conteúdo mais acessível e simplificado, denominada de IFRS for SME. A finalidade da norma é que essas empresas tenham um melhor padrão contábil, fazendo com que seus proprietários e usuários tomem melhores decisões com fundamento na qualidade das demonstrações financeiras (ALMEIDA et al., 2014; IUDÍCIBUS et al.,2010).

No Brasil, a convergência da norma é objeto da Resolução CFC $n^{\circ}$ 1.255/2009 que aprova a NBC TG 1000 - Contabilidade para Pequenas e Médias Empresas (CFC, 2009) e da Resolução CFC nº 1.418/2012 que aprova a ITG 1000 - Modelo Contábil para Microempresas e Empresas de Pequeno Porte (CFC, 2012).

Como ente fiscalizador da aplicação das normas, o Conselho Regional de Contabilidade do Estado do Rio Grande do Sul (CRCRS) (2014) elaborou um 
checklist com a finalidade de prevenção, mediante a orientação dos profissionais da Contabilidade sobre as principais questões abordadas pela Fiscalização e as irregularidades mais frequentes na elaboração das demonstrações contábeis.

Compõem o checklist itens sobre a Estrutura Conceitual Básica, sobre as demonstrações contábeis e respectivas notas explicativas, conforme descrito a seguir:

Bloco 1 - Estrutura Conceitual Básica

1. O Livro Diário apresenta as Demonstrações Contábeis de acordo com o item 3.17 da NBC TG 1000 ou com o item 10 da NBC TG 26.

2. Utilização de designações genéricas para contas com saldo superior ao percentual máximo permitido ( $10 \%$ do total do grupo - $\S 2^{\circ}$ art. 176 Lei 6.404/76).

3. Indicação da data de encerramento das Demonstrações Contábeis.

4. Divulgação do exercício de comparabilidade.

5. Indicação da categoria profissional e $\mathrm{n}^{\circ}$ de registro.

Bloco 2 - Balanço Patrimonial

6. Utilização de outros termos para identificar o Balanço Patrimonial (Balanço Geral, Balanço de Resultados etc.).

7. Destaque dos termos (Ativo Circulante e Não Circulante, Passivo Circulante e Não Circulante e Patrimônio Líquido).

8. Discriminação das contas que compõem o Ativo Não Circulante (Realizável a Longo Prazo, Investimentos, Imobilizado e Intangível).

9. Respeitados os saldos devedores e credores das contas patrimoniais.

10. Destaque das depreciações acumuladas no Ativo Não Circulante Imobilizado e das taxas praticadas (em Notas Explicativas).

11. Ordenação das contas do Patrimônio Líquido (Capital Social, Reservas de Capital, Ajustes de Avaliação Patrimonial, Reservas de Lucros, Ações/ Quotas em Tesouraria, Lucros Acumulados, Prejuízos Acumulados).

Bloco 3 - Demonstração do Resultado do Exercício

12. Estruturação indevida e/ou incompleta da Demonstração do Resultado e da Demonstração do Resultado Abrangente ao não destacar termos (Receitas, custo dos produtos/mercadorias/serviços, lucro bruto, resultados antes das receitas e despesas financeiras, resultado antes dos tributos sobre lucros, resultado líquido das operações continuadas, resultado líquido do período, resultado abrangente), conforme itens 5.7 e 5.8 da NBC TG 1000 ou com os itens 82 e 82.A da NBC TG 26. 
13. Uso de receitas e/ou despesas não operacionais de acordo com os itens 136 e 137 da CTG 02.

14. Utilização de outros termos para identificar a Demonstração do Resultado do Exercício.

Bloco 4 - Demonstração das Mutações do Patrimônio Líquido

15. Elaboração da DMPL em consonância com os itens 6.3 e 6.4 da NBC TG 1000 ou com o item 106 da NBC TG 26.

16. Utilização de outros termos para identificar a Demonstração das Mutações do Patrimônio Líquido.

Bloco 5 - Demonstração do Fluxo de Caixa (Exceto Micro e Pequena Empresa NBC TG 2000)

17. Estruturação da DFC - Modelo Direto e Indireto - de acordo com o item 7.3 da NBC TG 1000 e com os itens 10 a 12 e 20A da NBC TG 03.

18. Utilização de outros termos para identificar a Demonstração dos Fluxos de Caixa.

Bloco 6 - Demonstração do Valor Adicionado (Companhias de Capital Aberto)

19. A Demonstração do Valor Adicionado compõe o conjunto das Demonstrações Contábeis da Companhia de Capital Aberto, conforme estabelecido na NBC TG 09.

20. Utilização de outros termos para identificar a Demonstração do Valor Adicionado.

Bloco 7 - Demonstração de Lucros ou Prejuízos Acumulados - Demonstração do Resultado Abrangente

21. Estruturação da DLPA - de acordo com o item 6.5 da NBC TG 1000.

22. Estruturação da DRA - de acordo com o item 5.4 da NBC TG 1000.

23. Utilização de outros termos para identificar a Demonstração do Resultado Abrangente.

24. Utilização de outros termos para identificar a Demonstração de Lucros ou Prejuízos Acumulados.

Bloco 8 - Notas Explicativas

25. Contexto operacional.

26. Declaração de que as Demonstrações Contábeis foram elaboradas em conformidade com as normas de contabilidade e resumo das principais práticas contábeis adotadas no Brasil.

27. Apresentação das Notas Explicativas na ordem em que cada conta é apresentada nas Demonstrações Contábeis. 
28. Informação sobre a forma de tributação da empresa.

29. Informações sobre Provisões, Ativos e Passivos Contingentes.

30. Estoques (critério de avaliação, categorias de estoques, menção ao teste de recuperabilidade).

31. Imobilizado (método de cálculo da depreciação, vidas úteis e/ou taxas aplicadas, valor contábil bruto e depreciação acumulada, menção quanto à avaliação ao valor justo...).

32. Leasing financeiro (classificado como imobilizado, menção quanto às datas de início e fim, $\mathrm{n}^{\mathrm{o}}$ contrato, objeto).

33. Intangível (método de cálculo da amortização, vidas úteis e/ou taxas aplicadas, valor contábil bruto e amortização acumulada...).

34. Informações sobre empréstimos e/ou financiamentos.

35. Informações sobre composição do capital social.

36. Menção quanto a eventos subsequentes.

Para o profissional contábil, a importância em observar os itens do checklist, além da obrigação legal, está na qualificação das informações por ele prestadas. Para as organizações a transparência das informações para o mercado através de demonstrações contábeis que divulguem o seu real patrimônio econômico significa atribuir confiabilidade e maior credibilidade ao empreendimento.

\section{PROCEDIMENTOS METODOLÓGICOS}

Quanto à abordagem do problema, a pesquisa é caracterizada como qualitativa (MARCONI E LAKATOS, 2010), pela descrição dos benefícios das empresas em adotar as IFRS aplicadas as PMEs e quantitativa (RICHARDSON, 2012), pelas técnicas estatísticas utilizadas para analisar a aplicabilidade por parte das mesmas.

Em relação ao procedimento técnico classifica-se como pesquisa documental e levantamento (GIL, 2012) por coletar os dados nos demonstrativos contábeis das empresas e em entrevistas não-estruturadas com pessoas relacionadas a elas. Quanto ao objetivo, o a pesquisa é exploratória e descritiva (RICHARDSON, 2012: GIL, 2012), pela busca de maior profundidade e clareza das IFRS aplicadas às PMEs e por descrever as características de empresas que possuem escrituração contábil em escritórios de contabilidade na elaboração das demonstrações contábeis.

$\mathrm{O}$ alvo do estudo são as pequenas e médias empresas que possuem escrituração contábil em escritórios de contabilidade da Região do Vale do Taquari/ RS, das quais foram selecionadas 150 (cento e cinquenta) empresas pertencentes à carteira de clientes de um escritório de contabilidade. 
A coleta dos dados se utilizou de checklist (quadros 1 a 8) e de entrevistas (QUADRO 9). O checklist (COLAUTO; BEUREN, 2006) com 36 (trinta e seis) questões (CRCRS, 2014) foi aplicado nas demonstrações contábeis do exercício de 2015 e a entrevista (GIL, 2012) com 12 (doze) questões foi aplicada aos gestores das 10 (dez) maiores empresas em Receita Bruta no exercício de 2015, dentre as 150 (cento e cinquenta) selecionadas. $\mathrm{O}$ tratamento qualitativo dos dados foi realizado pela análise das respostas das entrevistas e o seu cruzamento com o respectivo item no checklist. O tratamento quantitativo ocorreu com o uso do software Microsoft Excel.

A limitação do método (RICHARDSON, 2012) fica restringida ao conteúdo disponível nos documentos analisados pelo checklist e disponibilizados pelo escritório de Contabilidade. Outra limitação do método é a falta de conhecimento das normas de Contabilidade pelos empresários, assim não se pode aprofundar muito o conteúdo das perguntas.

\section{RESULTADOS}

O presente capítulo retrata os principais resultados da pesquisa divididos em três etapas: (1) análise das demonstrações contábeis das empresas através da verificação dos 36 (trinta e seis) itens do checklist; (2) análise dos dados obtidos nas entrevistas, em que foi analisada a transparência das informações fornecidas pelas empresas ao escritório de Contabilidade; (3) análise dos resultados do checklist em comparação com os resultados das entrevistas.

\subsection{Verificação do checklist}

A verificação foi classificada em "atende plenamente", "atende parcialmente", "não atende" e "não se aplica". Os dados foram coletados com base na pesquisa documental das organizações selecionadas e analisados conforme a ordem prevista no checklist, iniciando-se pela verificação das demonstrações contábeis em relação a Estrutura Conceitual Básica. Foi constatado que o escritório de contabilidade prepara os demonstrativos de forma padrão para todas as empresas, já que o sistema de contabilidade utilizado padroniza as informações. 
Quadro 1 - Verificação da Estrutura Conceitual Básica

\begin{tabular}{|c|c|c|c|c|c|}
\hline & ESTRUTURA CONCEITUAL BÁSICA & $\begin{array}{c}\text { Atende } \\
\text { Plenamente }\end{array}$ & $\begin{array}{c}\text { Atende } \\
\text { Parcialmente } \\
\end{array}$ & $\begin{array}{c}\text { Não } \\
\text { Atende }\end{array}$ & $\begin{array}{l}\text { Não se } \\
\text { Aplica }\end{array}$ \\
\hline 1 & $\begin{array}{l}\text { O Livro Diário apresenta as Demonstrações Contábeis de acordo } \\
\text { com o item } 3.17 \text { da NBC TG } 1000 \text { ou com o item } 10 \text { da NBC TG } 26 .\end{array}$ & $\mathrm{X}$ & & & \\
\hline 2 & $\begin{array}{l}\text { Utilização de designações genéricas para contas com saldo superior } \\
\text { ao percentual máximo permitido ( } 10 \% \text { do total do grupo - } \S 2^{\circ} \text { art. } 176 \\
\text { Lei } 6.404 / 76) \text {. }\end{array}$ & & & & $\mathrm{x}$ \\
\hline 3 & Indicação da data de encerramento das Demonstrações Contábeis. & $x$ & & & \\
\hline 4 & Divulgação do exercício de comparabilidade. & $\bar{x}$ & & & \\
\hline 5 & Indicação da categoria profissional e nº de registro. & $\mathrm{X}$ & & & \\
\hline
\end{tabular}

Fonte: Adaptado pelo autor de CRCRS (2016).

Os dados do Quadro 2 demonstram que o livro diário das organizações apresenta as demonstrações contábeis de acordo com o item 3.17 da NBC TG 1000. Os demonstrativos apresentados pelas empresas foram: Balanço Patrimonial, Demonstração dos Lucros ou Prejuízos Acumulados, Demonstração do Resultado do Exercício, Demonstração do Fluxo de Caixa e Notas Explicativas.

No que tange os aspectos formais de apresentação, foi verificado que consta a data de encerramento e a comparabilidade nas demonstrações contábeis, juntamente com os dados do contador e o registro no CRC/RS. Já o item 2 não é aplicado as empresas analisadas, pois essas não estão sujeitas a Lei $6.404 / 76$.

Em relação à análise do Balanço Patrimonial apresentada no Quadro 3, foi constatada a identificação do nome do demonstrativo de forma correta, juntamente com os termos Ativo Circulante e Não Circulante e Passivo Circulante, Não Circulante e Patrimônio Líquido. Dentro das contas do Ativo Não Circulante, ambas foram apresentadas separadamente como Realizável a Longo Prazo, Investimentos, Imobilizado e Intangível. A verificação do Balanço Patrimonial segue o disposto na seção 4 da NBC TG 1000.

Outra informação apurada foi à correta divulgação quanto aos saldos das contas patrimoniais, respeitando a natureza devedora para as contas do ativo e credora para as do passivo.

Sobre as depreciações acumuladas, foi apurado que as empresas estão demonstrando os valores lançados em conta específica do Ativo Não Circulante, contudo, não estão publicando as taxas de depreciação praticadas aos itens do Ativo Imobilizado em Notas Explicativas. As taxas de depreciação utilizadas pelas empresas são as permitidas pela Legislação Fiscal, porém elas deveriam alocar o valor depreciável de ativo ao longo da sua vida útil. A divulgação das taxas de depreciação é uma exigência que consta da seção 17 da NBC TG 1000. 


\begin{tabular}{|l|l|c|c|c|}
\hline \multicolumn{1}{|c|}{ BALANÇo PATRIMONIAL } & $\begin{array}{c}\text { Atende } \\
\text { Plenamente }\end{array}$ & $\begin{array}{c}\text { Atende } \\
\text { Parcialmente }\end{array}$ & $\begin{array}{c}\text { Não } \\
\text { Atende }\end{array}$ & $\begin{array}{c}\text { Não se } \\
\text { Aplica }\end{array}$ \\
\hline 6 & $\begin{array}{l}\text { Utilização de outros termos para identificar o Balanço Patrimonial } \\
\text { (Balanço Geral, Balanço de Resultados, etc). }\end{array}$ & $\mathrm{X}$ & & \\
\hline 7 & $\begin{array}{l}\text { Destaque dos termos (Ativo Circulante e Não Circulante, Passivo } \\
\text { Circulante e Não Circulante e Patrimônio Líquido). }\end{array}$ & $\mathrm{X}$ & & \\
\hline 8 & $\begin{array}{l}\text { Discriminação das contas que compõem o Ativo Não Circulante } \\
\text { (Realizável a Longo Prazo, Investimentos, Imobilizado e Intangível). }\end{array}$ & $\mathrm{X}$ & $\mathrm{X}$ & \\
\hline 9 & $\begin{array}{l}\text { Respeitados os saldos devedores e credores das contas } \\
\text { patrimoniais. }\end{array}$ & & $\mathrm{X}$ \\
\hline 10 & $\begin{array}{l}\text { Destaque das depreciações acumuladas no Ativo Não Circulante } \\
\text { Imobilizado e das taxas praticadas (em Notas Explicativas). }\end{array}$ & & \\
\hline $\begin{array}{l}\text { Ordenação das contas do Patrimônio Líquido (Capital Social, } \\
\text { Reservas de Capital, Ajustes de Avaliação Patrimonial, Reservas de } \\
\text { Lucros, Ações/Quotas em Tesouraria, Lucros Acumulados, Prejuízos } \\
\text { Acumulados). }\end{array}$ & & $\mathrm{X}$ & \\
\hline
\end{tabular}

Fonte: Adaptado pelo autor de CRC/RS (2016).

Relativamente à ordenação das contas do Patrimônio Líquido, as contas Capital Social e Reservas de capital estão relacionadas no plano de contas das empresas. Nem todas as empresas, porém, possuem a conta Reserva de Lucros no plano de contas. Por sua vez, em algumas empresas a conta Lucros Acumulados e Prejuízos Acumulados está listada antes dos Ajustes de Avalição Patrimonial, sendo que essa última conta não foi relacionada. Outra conta que não foi encontra no plano de contas é Ações/Quotas em Tesouraria.

O Quadro 3 demonstra a verificação da demonstração do resultado do exercício. Analisando a DRE, foi constatado que as empresas estão utilizando o termo correto para a divulgação desse demonstrativo. Também foi verificado a não utilização das expressões Receitas e Despesas Não Operacionais por parte das empresas. Os aspectos relativos à apresentação da DRE constam na seção 5 da NBC TG 1000.

\section{Quadro 3 - Verificação da Demonstração do Resultado do Exercício}

\begin{tabular}{|c|c|c|c|c|c|}
\hline \multicolumn{2}{|r|}{ DEMONSTRAÇÃO DO RESULTADO DO EXERCÍCIO } & $\begin{array}{c}\text { Atende } \\
\text { Plenamente }\end{array}$ & $\begin{array}{c}\text { Atende } \\
\text { Parcialmente }\end{array}$ & $\begin{array}{l}\text { Não } \\
\text { atende }\end{array}$ & $\begin{array}{l}\text { Não se } \\
\text { Aplica }\end{array}$ \\
\hline 12 & $\begin{array}{l}\text { Estruturação indevida e/ou incompleta da Demonstração do } \\
\text { Resultado e da Demonstração do Resultado Abrangente, ao não } \\
\text { destacar termos (Receitas, custo dos produtos/mercadorias/serviços, } \\
\text { lucro bruto, resultados antes das receitas e despesas financeiras, } \\
\text { resultado antes dos tributos sobre lucros, resultado líquido das } \\
\text { operações continuadas, resultado líquido do período, resultado } \\
\text { abrangente), conforme itens } 5.7 \text { e } 5.8 \text { da NBC TG } 1000 \text { ou com os } \\
\text { itens } 82 \text { e 82.A da NBC TG } 26 \text {. }\end{array}$ & & $\mathrm{X}$ & & \\
\hline 13 & $\begin{array}{l}\text { Uso de receitas e/ou despesas não operacionais de acordo com os } \\
\text { itens } 136 \text { e } 137 \text { da CTG } 02 \text {. }\end{array}$ & $\mathrm{X}$ & & & \\
\hline 14 & $\begin{array}{l}\text { Utilização de outros termos para identificar a Demonstração do } \\
\text { Resultado do Exercício. }\end{array}$ & $\mathrm{X}$ & & & \\
\hline
\end{tabular}

Fonte: Adaptado pelo autor de CRC/RS (2016). 
Sobre a estrutura da demonstração do resultado do exercício, a análise demonstrou que não estão sendo destacados os termos Resultados Antes das Receitas e Despesas Financeiras e Resultado Líquido das Operações Continuadas, consequentemente não estão atendendo ao item 5.7 da NBC TG 1000 .

Quanto à obrigatoriedade da DMPL, as empresas analisadas tiveram apenas alterações em relação ao resultado do exercício, a distribuição de lucro e a correção de erros de períodos anteriores. Por conta disso, a DMPL foi substituída pela DLPA, não se aplicando a elaboração da mesma.

Quadro 4 - Verificação da Demonstração das Mutações do Patrimônio Líquido

\begin{tabular}{|c|c|c|c|c|c|}
\hline \multicolumn{2}{|r|}{ DEMONSTRAÇÃO DAS MUTAÇÕES DO PATRIMÔNIO LÍQUIDO } & \begin{tabular}{c|c} 
Atende \\
Plenamente
\end{tabular} & $\begin{array}{c}\text { Atende } \\
\text { Parcialmente }\end{array}$ & $\begin{array}{l}\text { Não } \\
\text { atende }\end{array}$ & $\begin{array}{l}\text { Não se } \\
\text { Aplica }\end{array}$ \\
\hline 15 & $\begin{array}{l}\text { Elaboração da DMPL em consonância com os itens } 6.3 \text { e } 6.4 \text { da NBC } \\
\text { TG } 1000 \text { ou com o item } 106 \text { da NBC TG } 26 .\end{array}$ & & & & $x$ \\
\hline 16 & $\begin{array}{l}\text { Utilização de outros termos para identificar a Demonstração das } \\
\text { Mutações do Patrimônio Liquido. }\end{array}$ & & & & $x$ \\
\hline
\end{tabular}

Fonte: Adaptado pelo autor de CRC/RS (2016).

A obrigatoriedade desse demonstrativo está disciplinada na seção 6 da NBC TG 1000 e a verificação está demonstrada no Quadro 5. Em relação à DFC, as empresas analisadas utilizaram o termo correto para identificar a sua divulgação.

Quadro 5 - Verificação da Demonstração das Mutações do Patrimônio Líquido

\begin{tabular}{|l|l|c|c|c|}
\hline \multicolumn{1}{|c|}{$\begin{array}{l}\text { DEMONSTRAÇÃo DO FLUXO DE CAIXA (Exceto Micro e Pequena } \\
\text { empresas - NBC TG 2000) }\end{array}$} & $\begin{array}{c}\text { Atende } \\
\text { Plenamente }\end{array}$ & $\begin{array}{c}\text { Atende } \\
\text { Parcialmente }\end{array}$ & $\begin{array}{c}\text { Não } \\
\text { atende }\end{array}$ & $\begin{array}{c}\text { Não se } \\
\text { Aplica }\end{array}$ \\
\hline 17 & $\begin{array}{l}\text { Estruturação da DFC - Modelo Direto e Indireto - de acordo com o } \\
\text { item } 7.3 \text { da NBC TG 1000 e com os itens 10 a 12 e 20A da NBC TG } \\
03 .\end{array}$ & $X$ & & \\
\hline 18 & $\begin{array}{l}\text { Utilização de outros termos para identificar a Demonstração dos } \\
\text { Fluxos de Caixa. }\end{array}$ & $X$ & & \\
\hline
\end{tabular}

Fonte: Adaptado pelo autor de CRC/RS (2016).

Como o escritório de contabilidade prepara as demonstrações financeiras de forma padrão para as empresas, ambas seguiram a estruturação utilizando o método indireto e separando as atividades em operacionais, investimento e financiamento, conforme seção 7 da NBC TG 1000.

A DVA é imposta apenas às organizações de capital aberto. Como as empresas analisadas são sociedades limitadas, elas não estão sujeitas a essa verificação, conforme consta no Quadro 6. 
Quadro 6 - Verificação da Demonstração do Valor Adicionado

\begin{tabular}{|c|l|c|c|c|}
\hline \multicolumn{1}{|l|}{$\begin{array}{c}\text { DEMONSTRAÇÃo DO VALOR ADICIONADO (Companhias de Capital } \\
\text { Aberto) }\end{array}$} & $\begin{array}{c}\text { Atende } \\
\text { Plenamente }\end{array}$ & $\begin{array}{c}\text { Atende } \\
\text { Parcialmente }\end{array}$ & $\begin{array}{c}\text { Não } \\
\text { atende }\end{array}$ & $\begin{array}{c}\text { Não se } \\
\text { Aplica }\end{array}$ \\
\hline 19 & $\begin{array}{l}\text { A Demonstração do Valor Adicionado compõe o conjunto das } \\
\text { Demonstrações Contábeis da Companhia de Capital Aberto, } \\
\text { Conforme estabelecido na NBC TG 09. }\end{array}$ & & & $X$ \\
\hline 20 & $\begin{array}{l}\text { Utilização de outros termos para identificar a Demonstração do Valor } \\
\text { Adicionado. }\end{array}$ & & & $X$ \\
\hline
\end{tabular}

Fonte: Adaptado pelo autor de CRC/RS (2016).

Analisando a DLPA, foi constatado que as empresas estão utilizando o termo correto para fazer a sua identificação. Por outro lado, a estrutura não está de acordo, já que os eventuais Ajustes em Razão de Correção de Erros de Períodos Anteriores não são apresentando por essas empresas.

Quadro 7 - Verificação da Demonstração de Lucros ou Prejuízos Acumulados/ Demonstração do Resultado Abrangente

\begin{tabular}{|c|c|c|c|c|c|}
\hline \multicolumn{2}{|r|}{$\begin{array}{c}\text { DEMONSTRAÇÃO DE LUCROS OU PREJUÍZOS } \\
\text { ACUMULADOS/DEMONSTRAÇÃO DO RESULTADO ABRANGENTE }\end{array}$} & $\begin{array}{c}\text { Atende } \\
\text { Plenamente }\end{array}$ & \begin{tabular}{c|c|} 
Atende \\
Parcialmente
\end{tabular} & $\begin{array}{c}\text { Não } \\
\text { atende }\end{array}$ & $\begin{array}{l}\text { Não se } \\
\text { Aplica }\end{array}$ \\
\hline 21 & Estruturação da DLPA - de acordo com o item 6.5 da NBC TG 1000 & & & $\mathrm{X}$ & \\
\hline 22 & Estruturação da DRA - de acordo com o item 5.4 da NBC TG 1000 & & & & $\bar{x}$ \\
\hline 23 & $\begin{array}{l}\text { Utilização de outros termos para identificar a Demonstração do } \\
\text { Resultado Abrangente. }\end{array}$ & & & & $X$ \\
\hline 24 & $\begin{array}{l}\text { Utilização de outros termos para identificar a Demonstração de } \\
\text { Lucros ou Prejuízos Acumulados. }\end{array}$ & $X$ & & & \\
\hline
\end{tabular}

Fonte: Adaptado pelo autor de CRC/RS (2016).

Já em relação à DRA, se constatou que as empresas não apresentam esse demonstrativo. Como as únicas alterações no patrimônio líquido das empresas analisadas foram apresentadas na DLPA, essas entidades não estão sujeitas ao demonstrativo. A obrigatoriedade desses demonstrativos consta respectivamente na seção 6 e 5 da NBC TG 1000, e a verificação está demonstrada no Quadro 8.

O último bloco do checklist verificou as informações que constavam nas Notas Explicativas das empresas com base na seção 8 da NBC TG 1000. 
Quadro 8 - Verificação das Notas Explicativas

\begin{tabular}{|c|c|c|c|c|c|}
\hline \multicolumn{2}{|r|}{ NOTAS EXPLICATIVAS } & $\begin{array}{c}\text { Atende } \\
\text { Plenamente }\end{array}$ & $\begin{array}{c}\text { Atende } \\
\text { Parcialmente }\end{array}$ & $\begin{array}{l}\text { Não } \\
\text { atende }\end{array}$ & $\begin{array}{l}\text { Não se } \\
\text { Aplica }\end{array}$ \\
\hline 25 & Contexto operacional. & $\bar{x}$ & & & \\
\hline 26 & $\begin{array}{l}\text { Declaração de que as Demonstrações Contábeis foram elaboradas } \\
\text { em conformidade com as normas de contabilidade e resumo das } \\
\text { principais práticas contábeis adotadas no Brasil. }\end{array}$ & & & $\mathrm{X}$ & \\
\hline 27 & $\begin{array}{l}\text { Apresentação das Notas Explicativas na ordem em que cada conta é } \\
\text { apresentada nas Demonstrações Contábeis. }\end{array}$ & & & $\mathrm{X}$ & \\
\hline 28 & Informação sobre a forma de tributação da empresa. & $\mathrm{X}$ & & & \\
\hline 29 & Informações sobre Provisões, Ativos e Passivos Contingentes. & & & $\mathrm{X}$ & \\
\hline 30 & $\begin{array}{l}\text { Estoques (critério de avaliação, categorias de estoques, menção ao } \\
\text { teste de recuperabilidade). }\end{array}$ & & $\mathrm{x}$ & & \\
\hline 31 & $\begin{array}{l}\text { Imobilizado (método de cálculo da depreciação, vidas úteis e/ou taxas } \\
\text { aplicadas, valor contábil bruto e depreciação acumulada, menção } \\
\text { quanto à avaliação ao valor justo...). }\end{array}$ & & $\mathrm{x}$ & & \\
\hline 32 & $\begin{array}{l}\text { Leasing financeiro (classificado como imobilizado, menção quanto às } \\
\text { datas de início e fim, } \mathrm{n}^{\circ} \text { contrato, objeto). }\end{array}$ & & & & $\mathrm{x}$ \\
\hline 33 & $\begin{array}{l}\text { Intangível (método de cálculo da amortização, vidas úteis e/ou taxas } \\
\text { aplicadas, valor contábil bruto e amortização acumulada...). }\end{array}$ & & & $\mathrm{x}$ & \\
\hline 34 & Informações sobre empréstimos e/ou financiamentos. & & $\mathrm{X}$ & & \\
\hline 35 & Informações sobre composição do capital social. & $\mathrm{X}$ & & & \\
\hline 36 & Menção quanto a eventos subsequentes. & & & $\mathrm{X}$ & \\
\hline
\end{tabular}

Fonte: Adaptado pelo autor de CRC/RS (2016).

Em relação ao contexto operacional das empresas, todas fizeram constar dados como: razão social, tipo jurídico, $\mathrm{n}^{\circ}$ do CNPJ, $\mathrm{n}^{\circ}$ do NIRE e data da inscrição na JUCERGS, endereço do estabelecimento e o objetivo social contendo as atividades realizadas pela empresa.

No que se refere à declaração de que as Demonstrações Contábeis foram elaboradas em conformidade com as normas de contabilidade e resumo das principais práticas contábeis adotadas no Brasil, as entidades analisadas trazem a seguinte menção: "Os registros e as Demonstrações Contábeis estão de acordo com as Normas Brasileiras de Contabilidade aplicáveis às empresas em geral, com observância, no que for permitido, da convergência às Normas Internacionais de Contabilidade, instituída pela Lei 11.638/2007, Lei 11.941/2009 e Resolução CFC 1.255 de 2009". A entidade, cujas demonstrações contábeis estiverem em conformidade com a NBC TG 1000 (Resolução CFC 1.255/09), deve fazer uma declaração explícita e sem reservas dessa conformidade nas notas explicativas, conforme item 3.3 da NBC TG 1000.

Com relação à apresentação da ordem em que cada conta é apresentada nas Demonstrações Contábeis, as poucas informações divulgadas não seguem a sequência de apresentação das contas nas demonstrações contábeis. Quanto à forma de tributação das empresas, foi constatado que todas as empresas apresentaram uma nota explicativa informando a sua forma de tributação, que nesses casos em análises eram Lucro Presumido ou Lucro Real. Em relação a informações sobre Provisões, Ativos e Passivos Contingentes, foi constatado que as empresas não divulgaram dados acerca desse item. 
Sobre as informações quando aos Estoques, todas as empresas analisadas mencionam em nota específica que o estoque foi avaliado pelo custo médio de aquisição. Por outro lado, em relação a categorias de estoques, não é mencionado o tipo de mercadoria ou produto que compõe os estoques. Também foi constatado que nenhuma das empresas menciona o teste de recuperabilidade, pois o mesmo não é realizado.

Relativamente ao Imobilizado, as notas explicativas mencionam que é demonstrado pelo valor de aquisição e as depreciações calculadas pelo método linear, através das taxas estabelecidas em função do tempo de vida útil, fixadas por espécie de bens, de acordo com parâmetros estabelecidos pela Legislação Tributária vigente. Entretanto, não mencionam a vida útil, taxas aplicadas, o valor contábil bruto e a amortização e o teste de recuperabilidade, que não é praticado.

Já em relação ao Leasing financeiro, foi constatado que as empresas analisadas não apresentaram esse tipo de operação. No que se refere ao Intangível (método de cálculo da amortização, vidas úteis e/ou taxas aplicadas, valor contábil bruto e amortização acumulada...), também foi constatado que as empresas não apresentaram informações quanto a esse item.

Quanto às informações sobre empréstimos e/ou financiamentos, as empresas divulgaram apenas que os saldos de empréstimos e financiamentos estão registrados pelos valores originais de captação. As entidades poderiam ainda colocar as informações de prazo de pagamento e taxas de juros para captação dos recursos.

Em relação às informações sobre composição do capital social, todas as empresas informaram a composição do capital social, sua integralização, a quantidade e o valor das quotas. E sobre a menção quanto a eventos subsequentes, foi constatado que as empresas não apresentaram informações sobre possíveis eventos subsequentes.

\subsection{Análise das entrevistas}

As informações a seguir foram coletadas através de uma entrevista direcionada aos gestores das 10 (dez) empresas selecionadas. O roteiro da entrevista foi constituído de 12 (doze) questões, elaboradas com o intuito de obter elementos acerca das informações fornecidas por essas empresas ao escritório de contabilidade.

O Quadro 9 demonstra a relação das perguntas e respostas dos entrevistados. As opções de resposta eram "Sim", "Não" e "Não se Aplica", sendo que essas deveriam ser justificadas. 
Quadro 9 - Perguntas e respostas dos gestores

\begin{tabular}{|c|c|c|c|}
\hline Perguntas & Sim & Não & \begin{tabular}{|l|} 
Não se Aplica \\
\end{tabular} \\
\hline $\begin{array}{l}1 \text { - A empresa pratica alguma atividade diferente daquelas relacionadas no contrato social? } \\
\text { Justifique. }\end{array}$ & 1 & 9 & 0 \\
\hline $\begin{array}{l}2 \text { - A empresa envia todos os documentos para serem contabilizados pelo escritório de } \\
\text { contabilidade? Justifique. }\end{array}$ & 5 & 5 & 0 \\
\hline $\begin{array}{l}3 \text { - O saldo da conta contábil clientes no Balanço Patrimonial é igual ao saldo dos controles } \\
\text { internos da empresa? Justifique. }\end{array}$ & 2 & 6 & 2 \\
\hline $\begin{array}{l}4 \text { - O saldo da conta contábil estoque no Balanço Patrimonial é igual ao saldo do inventário } \\
\text { levantado pela empresa? Justifique. }\end{array}$ & 3 & 7 & 0 \\
\hline $\begin{array}{l}5 \text { - É informado ao escritório de contabilidade se os itens do estoque e do imobilizado } \\
\text { sofreram eventual desvalorização? Justifique. }\end{array}$ & 0 & 10 & 0 \\
\hline $\begin{array}{l}6 \text { - Os bens do ativo imobilizado são utilizados restritamente para as atividades da empresa? } \\
\text { Justifique. }\end{array}$ & 9 & 1 & 0 \\
\hline $\begin{array}{l}7 \text { - O Saldo da conta contábil fornecedores no Balanço Patrimonial é igual ao saldo dos } \\
\text { controles internos da empresa? Justifique. }\end{array}$ & 4 & 5 & 1 \\
\hline $\begin{array}{l}8 \text { - As eventuais retiradas de lucros recebidos pelos sócios são informadas ao escritório de } \\
\text { contabilidade a fim de efetuar os registros contábeis? Justifique. }\end{array}$ & 3 & 7 & 0 \\
\hline $\begin{array}{l}9 \text { - Se a empresa faz operações de venda ou prestação de serviço com desconto, essa } \\
\text { informação é repassada ao escritório de contabilidade? Justifique. }\end{array}$ & 2 & 1 & 7 \\
\hline $\begin{array}{l}10 \text { - A empresa adquire mercadorias ou serviços sempre respaldados por documento hábil? } \\
\text { Se não, como procede? Justifique. }\end{array}$ & 4 & 6 & 0 \\
\hline $\begin{array}{l}11 \text { - A empresa demonstra a realidade por meio das suas demonstrações contábeis? } \\
\text { Justifique. }\end{array}$ & 4 & 6 & 0 \\
\hline $\begin{array}{l}12 \text { - Em relação ao sped contábil: você possui conhecimento suficiente quanto a sua } \\
\text { complexidade? Justifique. }\end{array}$ & 2 & 8 & 0 \\
\hline
\end{tabular}

Fonte: Do autor (2016).

Observando os dados da primeira pergunta, o resultado revela que 9 (nove) dos entrevistados responderam que a empresa não desenvolve atividades diferentes daquelas que estão elencados em seu contrato social. A maioria dos entrevistados relatou que, para desenvolver alguma atividade distinta, teria que alterar o objeto social. Um empresário justificou que participa de licitação pública e essa informação é verificada pelo licitante. Outro gestor respondeu inclusive que alguns fornecedores conferem se as operações estão de acordo com as constantes no contrato social. Por outro lado, apenas um administrador respondeu que a empresa presta serviços de locação de caçamba para entulhos e que essa atividade não está disposta no objeto social.

De acordo com os resultados demonstrados da pergunta 2 (dois), metade dos entrevistados responderam que a empresa envia todos os documentos contabilizáveis ao escritório contábil. A maioria dos empresários justificou que não envia todos os documentos, pois não são considerados documentos fiscais ou, ainda, não constam os dados da empresa nos documentos. Um administrador respondeu que não envia todas as despesas uma vez que quer demonstrar um resultado positivo e outro mencionou que a empresa faz operações que não são declaradas ao escritório de contabilidade.

A terceira pergunta buscou identificar se o saldo da conta clientes no Balanço Patrimonialé igual ao constante nos controles internos das organizações. O resultado demonstra que 6 (seis) empresas, que trabalham com operações 
a prazo, não estão evidenciando corretamente o saldo da conta clientes. A justificativa dos entrevistados se deu basicamente em função de que as vendas a prazo com cartão de crédito ou duplicata são consideradas operações de venda à vista pelo escritório de contabilidade. Outro ponto importante é que alguns clientes cobram juros nas vendas a prazo e essa informação não é informada à contabilidade. Cabe frisar que duas das empresas não praticam operações a prazo.

Analisando as respostas da quarta pergunta, 7 (sete) dos entrevistados responderam que o saldo da conta estoque no Balanço Patrimonial não é igual ao saldo do inventário. A principal justificativa é de que a empresa não faz a contagem física do estoque por falta de mão de obra e que no final do exercício é enviado ao escritório de contabilidade um relatório de estoque sem os devidos ajustes do inventário. Um empresário respondeu que a empresa tem estoque de materiais aplicados na construção civil, porém não é informado ao contador. Por outro lado, um dos entrevistados respondeu que no posto de combustível é feito o levantamento do estoque diariamente, e ao final do dia o ajuste das perdas em função da evaporação.

A quinta pergunta estava relacionada a uma eventual desvalorização dos itens do estoque e do imobilizado das empresas. Todos os entrevistados responderam que não informam ao escritório de contabilidade se esses itens estão desvalorizados, sendo que nesse caso as empresas podem estar com esses dados acima do seu valor recuperável no Balanço Patrimonial.

Em relação aos resultados apresentados na pergunta 6 (seis), foi constatado que 9 (nove) dos entrevistados utilizam seus imobilizados para uso restrito da organização. Os imobilizados citados para a justificativa são: caminhões para atividade de transporte; máquinas e equipamentos para indústria; móveis e utensílios e instalações para o comércio; ferramentas para a construção civil. Apenas um entrevistado respondeu que a empresa possui automóvel que é utilizado pelo sócio para uso particular, e justificou que os recursos de ambos se misturam.

Observando os resultados apresentados da sétima pergunta, 5 (cinco) dos entrevistados responderam que o saldo de fornecedores do balanço patrimonial não é igual aos controles internos da empresa. Esses empresários responderam que as empresas efetuam compras a prazo, mas para a contabilidade é considerada à vista e vice-versa. Outros 4 (quatro) gestores responderam que o saldo de fornecedores está de acordo, justificando que fazem a conferência e o fechamento mensal com o escritório contábil. Uma das empresas não efetua compras a prazo, justificando que o combustível só pode ser adquirido com pagamento adiantado.

A próxima pergunta questionou os entrevistados se eventuais retiradas de lucros pelos sócios são informadas ao escritório de contabilidade, sendo que 7 (sete) responderam que não. A maioria desses justificou que, no fechamento do exercício, as retiradas de lucros são contabilizadas visando à demonstração 
de imposto de renda dos sócios. Uma minoria respondeu que até retiram lucro, porém contabilmente a empresa apresenta prejuízos ou não tem caixa suficiente.

Sobre a nona pergunta, apenas 3 (três) dos 10 (dez) entrevistados responderam que fazem operações com desconto. Por sua vez, 2 (dois) desses relataram que essa informação é repassada ao escritório de Contabilidade, porém na DRE são considerados os valores líquidos sem os descontos. $\mathrm{O}$ administrador da outra empresa justificou dizendo que é contabilizado o valor líquido para facilitar a emissão da nota fiscal, e isso não é informado para a contabilidade.

Sobre os resultados apresentados na décima pergunta, foi constatado que 6 (seis) empresas adquirem algum tipo de mercadorias ou serviços sem o respaldo de documento hábil. A maioria desses entrevistados relatou que a empresa paga eventuais despesas com recibo para facilitar o pagamento, e assim dá a saída no caixa, porém esse documento não é lançado pelo escritório de contabilidade.

A pergunta 11 (onze) analisou se a empresa demonstra a realidade por meio das suas demonstrações contábeis, sendo que 6 (seis) dos entrevistados responderam que a empresa não está preocupada em demonstrar a realidade e justificaram dizendo que estão mesmo preocupados em pagar menos tributos. Os outros 4 (quatro) responderam que a empresa está preocupada em demonstrar a realidade e justificaram dizendo que tem sócios que não trabalham na empresa, ou em função de clientes e fornecedores ou até mesmo para uma melhor avaliação de crédito perante as instituições financeiras.

A última pergunta averiguou se o gestor possui conhecimento suficiente sobre a complexidade do SPED Contábil. Os resultados mostram que apenas 2 (dois) dos entrevistados responderam que sim, demonstrando saber que o livro diário é enviado aos sistemas SPED contendo as demonstrações contábeis. Em relação aos que não possuem conhecimento, ambos justificaram dizendo que o serviço de contabilidade é terceirizado e quem deveria entender desse assunto é o contador.

Após as análises individuais das questões, foi constatado que as empresas apresentam problemas em relação à veracidade e transparência das informações que constam em suas demonstrações contábeis. As respostas foram classificadas por grau de divergência conforme demonstra o Quadro 10. 
Quadro 10- Divergência nas respostas dos entrevistados

\begin{tabular}{|c|c|c|c|}
\hline \multicolumn{2}{|c|}{ Resumo das questões utilizadas nas entrevistas } \\
\hline \multirow{2}{*}{ Questões abordadas } & \multicolumn{2}{c|}{ Respostas } \\
\cline { 3 - 4 } & $\geq 50 \%$ & 9 & $75 \%$ \\
\hline \multirow{2}{*}{ Grau de divergência } & $<50 \%$ & 3 & $25 \%$ \\
\hline TOTAL & 12 & $100 \%$ \\
\hline
\end{tabular}

Fonte: Do autor (2016).

As práticas contábeis das organizações demonstram problemas relevantes quando as respostas apresentam um grau de divergência igual ou superior a $50 \%$, dessa forma elas estão contrariando as exigências previstas na NBC TG 1000. O Gráfico 1 ilustra o grau de divergência em relação às respostas encontradas.

Gráfico 1- Grau de divergência nas respostas

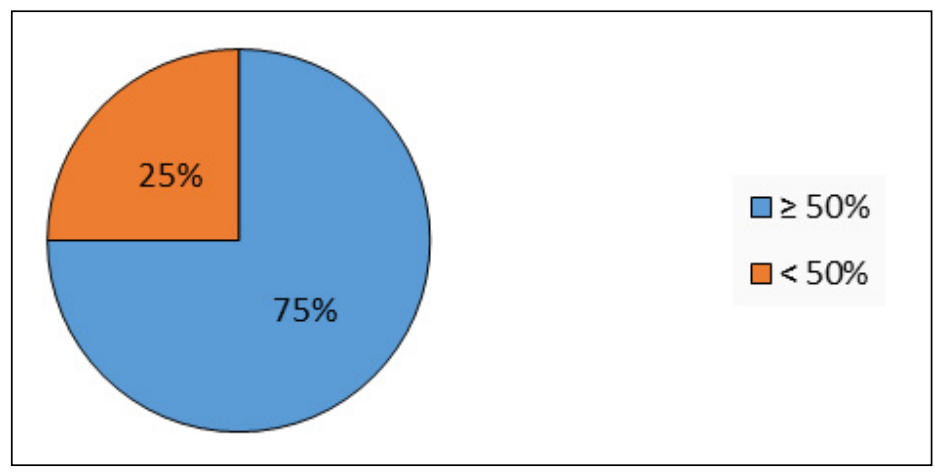

Fonte: Do autor (2016).

Observando os dados do Gráfico 1,75\% das respostas apresentaram problemas relevantes iguais ou superiores a 50\%. Isso confirma que as demonstrações contábeis não estão transparecendo à realidade das empresas, consequentemente os itens do checklist estão sendo atendidos de forma artificial.

Adicionalmente a análise das respostas dos entrevistados, será feito uma comparação entre a verificação do checklist e as repostas das entrevistas, visando esclarecer a real adoção as IFRSpelas PMEs, bem como relacionar os desafios e os benefícios que as mesmas possuem.

\subsection{Contraponto entre o checklist e as entrevistas}

Analisando os resultados do checklist, constatou-se que diversos itens atenderam a norma contábil, entretanto as respostas apresentadas pelos 
entrevistados evidenciaram que estão havendo distorções na apresentação das demonstrações contábeis.

Quadro 11 - Problemas relevantes x Divergência do checklist

\begin{tabular}{|c|c|}
\hline Problemas relevantes & Divergência do checklist \\
\hline $\begin{array}{l}\text { Não enviar todos os documentos para serem contabilizados pelo } \\
\text { escritório de contabilidade. }\end{array}$ & \multirow{9}{*}{$\begin{array}{l}\text { Estrutura Conceitual Básica, } \\
\text { Balanço Patrimonial, } \\
\text { Demonstração do Resultado } \\
\text { do Exercício, Demonstração } \\
\text { do Fluxo de Caixa, } \\
\text { Demonstração de Lucros ou } \\
\text { Prejuízos Acumulados e } \\
\text { Notas Explicativas. }\end{array}$} \\
\hline $\begin{array}{l}\text { Saldo da conta contábil clientes no Balanço Patrimonial diferente } \\
\text { do saldo dos controles internos. }\end{array}$ & \\
\hline $\begin{array}{l}\text { Saldo da conta contábil estoque no Balanço Patrimonial diferente } \\
\text { do saldo do inventário. }\end{array}$ & \\
\hline $\begin{array}{l}\text { Não informa o escritório de contabilidade se os itens do estoque e } \\
\text { do imobilizado sofreram desvalorização. }\end{array}$ & \\
\hline $\begin{array}{l}\text { Saldo da conta contábil fornecedores no Balanço Patrimonial } \\
\text { diferente do saldo dos controles internos. }\end{array}$ & \\
\hline $\begin{array}{l}\text { Retiradas de lucros recebidos pelos sócios são informadas ao } \\
\text { escritório de contabilidade. }\end{array}$ & \\
\hline $\begin{array}{l}\text { Adquire mercadorias ou serviços sem respaldados de documento } \\
\text { hábil. }\end{array}$ & \\
\hline $\begin{array}{l}\text { Não demonstra a realidade por meio das suas demonstrações } \\
\text { contábeis. }\end{array}$ & \\
\hline $\begin{array}{l}\text { Não possui conhecimento suficiente quanto a con } \\
\text { sped contábil. }\end{array}$ & \\
\hline
\end{tabular}

Fonte: Do autor (2016).

Os problemas relevantes encontrados nas práticas contábeis das empresas conflitam com os itens verificados pelo checklist e por consequência com as exigências da NBC TG 1000. Partindo das divergências constatadas entre as informações fornecidas pelas empresas ao escritório de contabilidade, serão elencados os desafios encontrados para adoção das IFRS pelas PMEs, tomando como base os autores citados na pesquisa.

Os autores Mourad e Paraskevopoulos (2010), enfatizam como pontos negativos na adoção das IFRS: aumento com alguns custos na divulgação das demonstrações contábeis; demanda maior de tempo para se adequar às novas rotinas. Já Almeida et al. (2014) sustenta que havia um paradigma do profissional contábil e da administração das entidades pois a elaboração das demonstrações contábeis no Brasil tinha forte influência da legislação fiscal

Os principais desafios encontrados na pesquisa para adoção das IFRS pelas PMEs foram:

- Conscientização dos empresários de que as demonstrações contábeis não são baseadas em regras fiscais;

- Transparência nas informações fornecidas pelas empresas ao escritório de contabilidade; 
- Maior custo com o escritório de contabilidade para adoção das IFRS;

- Qualificação por parte dos profissionais envolvidos;

Depois de elencar os desafios, serão discriminados os principais benefícios que as organizações possuem na adoção das IFRS pelas PMEs, também relacionados com autores já citados.

Os principais benefícios encontrados na pesquisa para adoção das IFRS pelas PMEs foram:

- Mais confiabilidade e transparência nas demonstrações contábeis;

- Diminuição das distorções nos dados das empresas;

- Maior eficiência na análise das demonstrações contábeis para a tomada de decisões;

- Atratividade de investidores.

Almeida et al. (2014) mencionam que pode ser destacado como principais benefícios: maior precisão na análise da situação econômica e do desempenho das empresas; elevar os níveis de qualidade e transparência das demonstrações contábeis; maior eficiência no processo de tomada de decisões. Já Mourad e Paraskevopoulos (2010) citam como pontos positivos para adoção das IFRS: maior transparência para os investidores; consistência e modernidade para empresas que adotam o IFRS; facilidade de captar crédito no mercado.

\section{CONSIDERAÇÕES FINAIS}

O checklist elaborado pelo CRCRS traz algumas das irregularidades mais frequentes encontradas nas demonstrações contábeis, sendo utilizado nessa pesquisa para verificar a adequação das pequenas e médias empresas da Região do Vale do Taquari/RS às Normas Internacionais de Contabilidade pelas PMEs. Os resultados encontrados demonstram que essas organizações estão infringindo em algumas irregularidades já elencadas pelo CRCRS.

A maior divergência constatada está na elaboração das notas explicativas, já que as empresas não apresentaram declaração explícita de conformidade total com a NBC TG 1000, bem como informações acerca das principais práticas contábeis e ainda os dados detalhados sobre os Estoques, Imobilizado, Intangível, Empréstimos e Financiamentos. Também foi constatado que as empresas não estão aplicando o teste de recuperabilidade em seus ativos e não estão estruturando algumas demonstrações contábeis conforme a NCB TG 1000 .

Por sua vez, a entrevista tinha o objetivo de saber se as informações contábeis fornecidas por essas empresas ao escritório de contabilidade eram idôneas e transparentes. Os resultados apontaram que as demonstrações contábeis das empresas não estão condizendo com a essência econômica dos fatos, consequentemente alguns itens que foram verificados como atendidos 
no checklist estão em desacordo. Também, foi observado que os empresários demonstram estar mais preocupados em pagar menos tributos do que em apresentar a realidade das empresas por meio das demonstrações contábeis.

Da mesma forma, foi constatado que $75 \%$ das respostas das entrevistas apresentaram problemas relevantes nas organizações, descumprindo as exigências previstas na NBC TG 1000. Portanto, conclui-se que se as mesmas não estão transparecendo, todas as informações necessárias para a elaboração das demonstrações contábeis, certamente o escritório de contabilidade não terá condições de fazê-lo de forma precisa.

Por fim, além dos benefícios já elencados anteriormente, a presente pesquisa é também um dos principais benefícios encontrados na adoção das Normais Internacionais de Contabilidade pelas PMEs. Por se tratar de um tema relativamente novo para as empresas que possuem escrituração contábil em escritórios de contabilidade, entende-se que o estudo pode proporcionar um aprimoramento para a contabilidade dessas empresas.

\section{REFERÊNCIAS}

ALMEIDA, José E. F. et al. Contabilidade das pequenas e médias empresas. 1. ed. Rio de Janeiro: Elsevier, 2014.

BEUREN, Ilse M. (Org.). Como elaborar trabalhos monográficos em contabilidade: teoria e prática. 3. ed. São Paulo: Atlas, 2006.

BRASIL. Decreto n. 6.022, de 22 de janeiro de 2007. Institui o Sistema Público de Escrituração Digital - SPED. Disponível em: <http:/ /www.planalto.gov.br/ ccivil_03/_ato2007-2010/2007/Decreto/D6022.htm>. Acesso em: 12 out. 2016.

. Lei n. 6.404, de 15 de dezembro de 1976. Dispõe sobre as Sociedades por

Ações. Disponível em: <http://www.planalto.gov.br/ccivil_03/leis/L6404consol. htm>. Acesso em: 3 abr. 2016.

. Lei n. 11.638, de 28 de dezembro de 2007. Altera e revoga dispositivos da Lei n. 6.404, de 15 de dezembro de 1976, e da Lei n. 6.385, de 7 de dezembro de 1976, e estende às sociedades de grande porte disposições relativas à elaboração e divulgação de demonstrações financeiras. Disponível em: <http://www.planalto.gov.br/ ccivil_03/_ato2007-2010/2007/lei/111638.htm>. Acesso em:20abr. 2016.

. Lei Complementar no 123 , de 14 de dezembro de 2006. Institui o Estatuto Nacional da Microempresa e da Empresa de Pequeno Porte. Disponível em:<http:/ / www.receita.fazenda.gov.br/Legislacao/LeisComplementares/2006/leicp123.htm>. Acesso em: 20 abr. 2016.

CONSELHO FEDERAL DE CONTABILIDADE - CFC. Resolução CFC n. 1.055, de 7 de outubro de 2005.Cria o COMITÊ DE PRONUNCIAMENTOS CONTÁBEIS 
(CPC). Disponível em: <http://www2.cfc.org.br/sisweb/sre/detalhes_sre. aspx?Codigo=2005/001055>. Acesso em: 6 abr. 2016.

. Resolução CFC n. 1.255, de 10 de dezembro de 2009. Aprova a NBC TG 1000 Contabilidade para Pequenas e Médias Empresas. Disponível em:<http:/ / www2.cfc. org.br/sisweb/sre/detalhes_sre.aspx?Codigo=2009/001255>. Acesso em: 2 mai. 2016.

Resolução CFC n. 1.328, de 18 de março de 2011. Dispõe sobre a Estrutura das Normas Brasileiras de Contabilidade. Disponível em:<http:/ /www2.cfc.org.br/ sisweb/sre/detalhes_sre.aspx?Codigo=2011/001328>. Acesso em: 2 mai. 2016.

Resolução CFC n. 1.418, de 5 de dezembro de 2012. Aprova a ITG 1000 Modelo Contábil para Microempresa e Empresa de Pequeno Porte. Disponível em: <http:/ / www2.cfc.org.br/sisweb/sre/detalhes_sre.aspx?Codigo=2012/001418>. Acesso em: 5 mai. 2016.

. Norma Brasileira de Contabilidade - CTG 2001 (R2), de 15 de abril de 2016 - Altera o Comunicado Técnico CTG 2001 (R1) que define as formalidades da escrituração contábil em forma digital para fins de atendimento ao Sistema Público de Escrituração Digital (SPED). Disponível em: <http:/ / www1.cfc.org.br/sisweb/sre/ detalhes_sre.aspx?codigo=2016/CTG2001(R2)>. Acesso em: 12 out. 2016.

. Norma Brasileira de Contabilidade - ITG2000 (R1), de 5 de dezembro de 2014 - Altera a Interpretação Técnica ITG 2000 que dispõe sobre a escrituração contábil. Disponível em: <http:/ / www1.cfc.org.br/sisweb/sre/detalhes_sre. aspx?Codigo=2014/ITG2000(R1)>. Acesso em: 12 out. 2016.

\section{CONSELHO REGIONAL DE CONTABILDIADE DO ESTADO DO RIO GRANDE} DO SUL - CRCRS. Cartilha Orientativa de Fiscalização. 2014. Disponível em: http:/ / www.crcrs.org.br/wp-content/uploads/2014/01/cartilha_fiscalizacao2014. pdf?ef3d49\&3e9f43. Acesso em: 5 ago. 2016.

GIL, Antonio C. Métodos e técnicas de pesquisa social.6. ed. São Paulo: Atlas, 2012.

GIROTTO, Maristela. Brasil começa a adotar o IFRS na contabilidade de PMEs.

Revista Brasileira de Contabilidade, Brasília, n. 186, nov./dez. 2010. Disponível em: <http:/ / www.fucape.br/downloads/reportagem_rbc_186.pdf>. Acesso em: 14 abr. 2016.

IASB - International Accounting Standard Board.IFRS for SMEs: Adoption and Implementation. Disponível em:<http:/ / www.iasb.org/NR/rdonlyres/2E9A655483FD-4B50-9D34-3822374F059C/0/presentationAdoptionandImplementationSMEs. pdf.> Acesso em: 16 abr. 2016.

IUDÍCIBUS, Sérgio de. et al. Manual de contabilidade societária. São Paulo: Atlas, 2010.

MARCONI, Marina A.; LAKATOS, Eva M. Fundamentos de metodologia científica. 7. ed. São Paulo: Atlas, 2010. 
MOURAD, Nabil A.; PARASKEVOPOULOS, Alexandre. IFRS: introdução às normas internacionais de contabilidade. 2. ed. São Paulo: Atlas, 2010.

RICHARDSON, Roberto J. Pesquisa social: métodos e técnicas. 3. ed. São Paulo: Atlas, 2012.

SERVIÇO BRASILEIRO DE APOIO ÀS MICRO E PEQUENAS EMPRESAS - SEBRAE. Participação das Micro e Pequenas Empresas na Economia Brasileira. Jul. 2014.

Disponível em: <http:/ / www.sebrae.com.br/estudos-e-pesquisas>. Acesso em: 06 abr. 2016. 